\title{
Rendimento de cultivares de maxixe em função de épocas de plantio.
}

\author{
Geraldo M. de Resende
}

Embrapa Semi-Árido, C. Postal 23, 56300-000 Petrolina-PE

RESUMO

Com o objetivo de identificar cultivares de maxixe mais produtivas e melhores épocas de plantio, instalou-se oito ensaios no Campo Experimental do Gorutuba, Porteirinha-MG. O delineamento experimental foi de blocos ao acaso em parcelas subdivididas, sendo as parcelas constituídas pelas quatro épocas de plantio (novembro, fevereiro, maio e agosto) e as subparcelas pelas cultivares regionais de maxixe (Liso, Semi-Liso, Espículos e Quinado) e cultivares comerciais (Maxixe do Norte Topseed e Corradini) com cinco repetições. As cultivares regionais sobressaíram-se em rendimento, destacando-se a cultivar de maxixe Quinado como a mais produtiva $\left(17,50\right.$ t.ha $\left.^{-1}\right)$ e com maior peso médio de fruto $(45,69 \mathrm{~g} /$ fruto), enquanto as cultivares de maxixe Liso e Semi-liso apresentaram o maior número de frutos por planta $(28,01$ e 25,94 frutos/planta, respectivamente). As melhores épocas foram os meses de fevereiro e agosto, sendo o menor rendimento apresentado no período de maior ocorrência de temperaturas mais baixas (maio).

Palavras-chave: Cucumis anguria, épocas de cultivo, peso médio de fruto, número de frutos por planta.

\begin{abstract}
Influence of planting dates on indian gherkin cultivar's yield.

The objective of the study was to identify more productive indian gherkin cultivars under different planting dates. Eight trials were carried out at the Gorutuba Experimental Station, Porteirinha-MG, Brazil. A split-plot complete randomized block design was used, with main plots made up of planting dates (November, February, May and August) and subplots by local cultivars (Indian Gherkin Smooth, Semi-smooth, with Spines and Smooth Quinate) and commercial cultivars (North Indian Gherkin Topseed and Corradini), with five replications. The local cultivars showed the greatest yield, and the Smooth Quinate cultivars, the highest yield (17.50 ton.ha $\left.{ }^{-1}\right)$ and mean fruits weight ( $45.69 \mathrm{~g} /$ fruit), whereas the Smooth and Semismooth cultivars showed the highest number of fruits per plant (28.01 and 25.94 fruits/plant, respectively). The February and August planting dates resulted in the highest yield, whereas the lowest yield occurred in the winter season (May).
\end{abstract}

Keywords: Cucumis anguria, fruit mean weight, number of fruits per plant.

\section{(Aceito para publicação em 22 de setembro de 1998)}

$\mathrm{O}$ maxixe (Cucumis anguria L.) é originário da África Tropical, tendo como ancestral à espécie Cucumis longipes, de frutos amargos, a qual, através de mutação natural, deu origem à espécie Cucumis anguria L. É cultivado esporadicamente em áreas concentradas na região de clima tropical e subtropical, principalmente no Brasil e Caribe. No Brasil a maior área de produção ocorre nas regiões de forte influência da cultura africana (Norte, Nordeste e Sudeste) onde há plantas em estado semi-selvagem, subespontâneo e em cultivos consorciados com cereais (Yokoyama \& Silva Júnior, 1988). Queiroz (1993), relatou que em Tacaimbó-PE, além de cultivado no período das chuvas, o maxixe é cultivado no período seco sob regime irrigado.

Pouco cultivado no Centro-Sul do Brasil, ocupa posição de destaque como uma iguaria muito apreciada no Norte de Minas Gerais, nos estados do Nordeste, Rio de Janeiro e São Paulo, que destacam-se como os principais mercados consumidores. Trata-se de uma planta rústica, cujos frutos são utilizados na alimentação humana, sendo consumidos cru em saladas, cozidos ou na forma de picles (Tindall, 1983; Baird \& Thieret, 1988). É alimento basicamente energético, sendo uma fonte valiosa de vitaminas e sais minerais (Martins, 1986) e quando consumido in natura na forma de saladas, substitue com vantagem o pepino, por ser menos indigesto (Corrêa, 1974). O maxixe mostra-se como uma hortaliça de grande potencialidade como alternativa ao pepino para consumo em conserva (Koch \& Costa, 1991).

$\mathrm{Na}$ região metropolitana do estado do Rio de Janeiro o consumo por comensal/ano de frutos de maxixe é de 1,0 $\mathrm{kg}$, enquanto em Belo Horizonte é de $0,8 \mathrm{~kg}$ (Saturnino et al., 1982). Acredita-se que atualmente esse consumo esteja a níveis superiores e que no Norte de Minas Gerais e nos estados do Norte e Nordeste do Brasil esse consumo seja ainda mais elevado, devido principalmente, ao hábito alimentar regional e a cultura encontrar condições edafo- climáticas favoráveis ao seu desenvolvimento.

É uma espécie de clima quente, suportando temperatura e pluviosidade elevadas (Yokoyama \& Silva Junior, 1988). No Rio de Janeiro semeia-se de agosto a novembro, podendo ser plantado durante o ano todo em localidades baixas e quentes, e de setembro a fevereiro em zonas de serra (Filgueira, 1981). No Maranhão o cultivo ocorre durante o ano inteiro sendo a maior concentração nos meses de julho a dezembro, quando a precipitação é mais escassa. No período chuvoso há uma redução bastante acentuada de plantio (Martins, 1986).

Existem duas cultivares de maxixe, uma com frutos de espículos carnosos e outra com frutos lisos, sendo que a aceitação no mercado da Amazônia independe desta característica (Pimentel, 1985). Ao contrário, no Rio de Janeiro parece haver uma preferência por frutos mais lisos (Filgueira, 1981). A população brasileira de maxixe é caracterizada pela produção de frutos compridos, lisos e 
não amargos (Paterniani \& Costa, 1992), com frutos ovais a oblongos, de 4 a 5 $\mathrm{cm}$ de comprimento e 3 a $4 \mathrm{~cm}$ de diâmetro (Tindall, 1983).

As cultivares lisas produzem 30 frutos/cova com peso médio de $30 \mathrm{~g} /$ fruto, e as cultivares com espículos rendem 32 frutos/cova com peso médio por fruto de $36 \mathrm{~g}$, em período chuvoso, com 3 plantas/cova. No período seco com irrigação, a cultivar lisa produziu 110 frutos/cova, com peso médio de $37 \mathrm{~g} /$ fruto e a com espículos apresentou 165 frutos/cova e peso médio de fruto de $38 \mathrm{~g}$, salientando que o espaçamento usado foi de 3,0 x 2,0 m (Pimentel, 1985).

Informa Filgueira (1981) que a colheita inicia-se aos 60-70 dias após a semeadura, prolongando-se por um período de 3 meses ou mais, com rendimento de 5 t.ha $^{-1}$. Enquanto Kurihara et al. (1993) salientaram que em Brasília, o período de entressafra ocorre nos meses de junho a outubro quando se obtém as maiores cotações de preços, indicando um rendimento de 6 a $8 \mathrm{t} / \mathrm{ha}^{-1}$, para a cultivar utilizada (Semi-liso). O maxixe é cultivado o ano inteiro no Maranhão, com rendimento médio de 16 t.ha-1 na maior parte do ano, sendo porém a área de plantio reduzida no período chuvoso, quando o rendimento também diminuiu para 8-10 t.ha-1 . A produtividade é variável segundo a população de cultivo (Martins, 1986). Um estudo com 23 populações brasileiras e uma boliviana com transplantio das mudas em setembro, revelou rendimento variando de 6,6 a 17,1 t.ha ${ }^{-1}$, no espaçamento de $1,5 \mathrm{~m} \mathrm{x} \mathrm{1,0} \mathrm{m,} \mathrm{em} 9$ colheitas. O número de frutos por planta variou de 27 a 86 unidades e o peso médio oscilou de 34 a $70 \mathrm{~g} /$ fruto com maior concentração no intervalo de 40 a $50 \mathrm{~g} /$ fruto. $\mathrm{O}$ diâmetro do fruto variou de 3,67 a 4,63 cm e o seu comprimento de 4,98 a 6,65 cm (Yokoyama, 1987).

A carência de informações técnicas a respeito da cultura, sua capacidade de produzir mesmo em condições desfavoráveis de clima (seco e temperatura elevada), a demanda crescente e boa aceitação nos principais mercados consumidores nacionais, justificou o presente trabalho. Objetivou-se avaliar o comportamento de cultivares regionais e comerciais de maxixe em épocas de plantio com maior potencial produtivo e melhor aceitação do mercado consumidor.

Tabela 1. Valores mensais de precipitação pluviométrica $(\mathrm{mm})$, insolação (horas acumuladas) temperatura $\left({ }^{\circ} \mathrm{C}\right)$ e umidade relativa do ar $(\%)$ média, durante a execução dos experimentos. EPAMIG, Porteirinha - MG, 1986 a 1988.

\begin{tabular}{lrrrrrrrrr}
\hline \multirow{2}{*}{ Meses } & \multicolumn{2}{c}{$\begin{array}{c}\text { Prec. } \\
\text { pluviométrica }\end{array}$} & \multicolumn{2}{c}{ Temperatura } & \multicolumn{2}{c}{$\begin{array}{c}\text { Umidade } \\
\text { Relativa }\end{array}$} & \multicolumn{2}{c}{ Insolação } \\
\cline { 2 - 10 } & Ano 1* & Ano 2** & Ano 1 & Ano 2 & Ano 1 & Ano2 & Ano 1 & Ano2 \\
\hline Novembro & 43,5 & 90,9 & 25,2 & 26,1 & 64 & 67 & 198,6 & 168,7 \\
Dezembro & 159,5 & 324,9 & 25,8 & 25,6 & 70 & 78 & 181,6 & 152,2 \\
Janeiro & 121,0 & 38,6 & 26,2 & 26,4 & 66 & 66 & 292,0 & 271,9 \\
Fevereiro & 2,7 & 78,0 & 27,3 & 26,7 & 58 & 63 & 249,7 & 239,1 \\
Março & 119,7 & 104,0 & 25,8 & 25,4 & 70 & 72 & 226,0 & 216,2 \\
Abril & 43,9 & 32,7 & 25,4 & 24,6 & 67 & 65 & 248,2 & 272,1 \\
Maio & 14,2 & 0,0 & 24,6 & 24,5 & 65 & 58 & 281,3 & 286,5 \\
Junho & 0,0 & 0,0 & 23,5 & 22,5 & 62 & 58 & 254,2 & 264,5 \\
Julho & 0,0 & 0,0 & 23,5 & 21,3 & 58 & 59 & 296,5 & 270,0 \\
Agosto & 0,0 & 0,0 & 24,3 & 24,0 & 54 & 64 & 310,0 & 286,0 \\
Setembro & 59,3 & 0,0 & 25,5 & 25,5 & 62 & 63 & 247,2 & 223,5 \\
Outubro & 22,3 & 88,9 & 27,7 & 26.1 & 59 & 60 & 277,2 & 223,5 \\
\hline
\end{tabular}

* Ano 1 (Novembro/86 a Outubro/87)

** Ano 2 ( Novembro/87 a Outubro/88)

\section{MATERIAL E MÉTODOS}

Os experimentos foram conduzidos no Campo Experimental do Gorutuba, Porteirinha-MG, em clima segundo a classificação de Köppen, do tipo Aw com verão chuvoso (outubro a março) e inverno seco (abril a setembro) em solo aluvião eutrófico, textura arenosa. Os dados climáticos durante a execução dos experimentos são apresentados na Tabela 1. O delineamento experimental foi de blocos ao acaso, em parcelas subdivididas, onde as parcelas foram constituídas pelas quatro épocas de plantio (novembro, fevereiro, maio e agosto) e as subparcelas pelas cultivares regionais de maxixe (Liso, Semi-liso, Quinado e Espículos) e cultivares comerciais (Maxixe do Norte Topseed - Norte T e Maxixe do Norte Corradini - Norte C) com cinco repetições. As subparcelas constituíram-se de quatro linhas de 7,0 x 1,0 $\mathrm{m}\left(28,0 \mathrm{~m}^{2}\right)$ onde a área útil foram as 2 linhas centrais, retirando-se um metro em cada extremidade. As covas espaçadas de $1,0 \mathrm{~m}$, foram adubadas com $50 \mathrm{~g}$ da fórmula 4-30-16, sendo que após o desbaste deixou-se 2 plantas/cova. Por ocasião do desbaste e 30 dias após foram feitas adubações em cobertura empregando-se com $50 \mathrm{~g} /$ cova de sulfato de amônio em cada aplicação.
Os plantios foram realizados no dia cinco do mês de cada época nos anos de 1986/87 e 1987/88, sendo as irrigações por sulcos de infiltração em intervalos de três dias até 20 dias após a semeadura e posteriormente semanais, com lâminas em torno de $30 \mathrm{~mm}$. Foram realizadas pulverizações semanais contra pulgões e vaquinhas com Pirimicarb e Triclorfon, respectivamente.

As colheitas (frutos imaturos) iniciaram-se aos 55-65 dias da semeadura sendo realizadas uma vez por semana, por um período de 45 dias (sete colheitas) para os plantios de maio e agosto, 35 dias ( 6 colheitas) para fevereiro e 30 dias (cinco colheitas) para novembro. Foram avaliadas as seguintes características: rendimento (t.ha-1), peso médio de fruto $(\mathrm{g})$, número de frutos por planta, diâmetro transversal e comprimento de fruto $(\mathrm{cm})$. Os efeitos dos fatores estudados sobre as características estudadas foram conhecidos mediante a análise de variância e comparação das médias pelo teste de Tukey a 5\% de probabilidade (Gomes, 1987).

\section{RESULTADOS E DISCUSSÃO}

Os resultados evidenciaram efeitos significativos para cultivares, época de 
RESENDE, G. M. de. Rendimento de cultivares de maxixe em função de épocas de plantio.

Tabela 2. Rendimento (t.ha ${ }^{-1}$ ) de cultivares de maxixe em função das épocas de plantio. EPAMIG, Porteirinha-MG', 1986 a 1988.

\begin{tabular}{|c|c|c|c|c|c|}
\hline \multirow{2}{*}{ Cultivares } & \multicolumn{4}{|c|}{ Épocas de plantio } & \multirow{2}{*}{ Médias } \\
\hline & Novembro & Fevereiro & Maio & Agosto & \\
\hline Liso & $9,27 * b$ & $22,02 \quad b$ & $4,68 \mathrm{ab}$ & $20,41 \mathrm{~b}$ & $14,10 \mathrm{~b}$ \\
\hline Semi-liso & $9,73 \mathrm{~b}$ & 18,09 & $4,21 \mathrm{ab}$ & $18,56 \mathrm{bc}$ & $12,65 \mathrm{~b}$ \\
\hline Norte-C & $3,28 \quad \mathrm{c}$ & $10,58 \quad d$ & $2,15 \quad b$ & $10,30 \quad d$ & $6,58 \quad \mathrm{c}$ \\
\hline Norte-T & $3,10 \quad \mathrm{c}$ & $13,39 \quad \mathrm{~d}$ & $2,90 \mathrm{ab}$ & $12,15 \quad \mathrm{~d}$ & $7,89 \quad \mathrm{c}$ \\
\hline Espículos & $9,42 \mathrm{~b}$ & $20,95 \mathrm{bc}$ & $3,60 \mathrm{ab}$ & $17,12 \mathrm{c}$ & $12,77 \mathrm{~b}$ \\
\hline Quinado & $14,21 \mathrm{a}$ & $26,15 \mathrm{a}$ & $5,34 \mathrm{a}$ & $24,29 \mathrm{a}$ & $17,50 \mathrm{a}$ \\
\hline Médias & $8,17 \mathrm{C}$ & $18,53 \mathrm{~A}$ & $3,81 \mathrm{D}$ & $17,14 \mathrm{~B}$ & \\
\hline C.V. $(\%)$ & Cultiv & 20,37 & &, 32 & \\
\hline
\end{tabular}

${ }^{1}$ Média de dois anos.

*Médias seguidas pela mesma letra minúscula na coluna e maiúscula na linha, não diferem entre si pelo teste de Tukey ao nível de 5\% de probabilidade.

Tabela 3. Peso médio de frutos (g) de cultivares de maxixe em função das épocas de plantio. EPAMIG, Porteirinha-MG ${ }^{1}, 1986$ a 1988.

\begin{tabular}{|c|c|c|c|c|c|}
\hline \multirow{3}{*}{$\begin{array}{l}\text { Cultivares } \\
\text { Liso }\end{array}$} & \multicolumn{4}{|c|}{ Épocas de plantio } & \multirow{2}{*}{ Médias } \\
\hline & Novembro & Fevereiro & Maio & Agosto & \\
\hline & $26,46 \quad b$ & $28,68 \quad b$ & $25,39 \quad b$ & $28,91 \quad b$ & $27,35 \quad b$ \\
\hline Semi-liso & $26,36 \mathrm{~b}$ & $27,90 \quad b$ & $22,30 \quad c$ & $27,99 \quad b$ & $26,01 \quad \mathrm{c}$ \\
\hline Norte-C & $18,99 \quad \mathrm{c}$ & $18,55 \quad \mathrm{~d}$ & 14,57 & $19,02 \quad \mathrm{c}$ & 17,78 \\
\hline Norte-T & 19,23 & $22,30 \quad c$ & 17,15 & 19,20 & $19,47 \quad \mathrm{~d}$ \\
\hline Espículos & $27,07 \quad b$ & $27,82 \quad b$ & $23,03 \quad b c$ & $26,51 \quad b$ & $26,11 \quad b c$ \\
\hline Quinado & $48,18 \mathrm{a}$ & $49,90 \mathrm{a}$ & $36,99 \mathrm{a}$ & $47,74 \mathrm{a}$ & $45,70 \mathrm{a}$ \\
\hline Médias & $27,71 \mathrm{~B}$ & $29,11 \mathrm{~A}$ & $23,24 \mathrm{C}$ & $28,23 \mathrm{AB}$ & \\
\hline C.V.(\%) & Culti & 7,29 & Époc & 44 & \\
\hline
\end{tabular}

${ }^{1}$ Média de dois anos.

*Médias seguidas pela mesma letra minúscula na coluna e maiúscula na linha, não diferem entre si pelo teste de Tukey ao nível de $5 \%$ de probabilidade.

plantio e interação cultivares $\mathrm{x}$ épocas de plantio, para todas as características em estudo, contudo sem nenhum efeito para os anos de estudo.

Os rendimentos variaram de 2,15 a 26,15 t.ha ${ }^{-1}$ nas diferentes épocas de plantio (Tabela 2). A melhor época de plantio foi no mês de fevereiro que apresentou rendimentos entre 10,58 e 26,15 t.ha ${ }^{-1}$, seguida pelos meses de agosto e novembro, tendo o plantio no mês de maio apresentado o pior desempenho, com rendimento máximo alcançado pela cultivar Quinado de 5,34 t.ha ${ }^{-1}$. Estes menores rendimentos ocorridos nos plantios de maio e novembro devem-se provavelmente à ocorrência de temperaturas mais baixas (maio), chuvas e menor luminosidade (novembro) (Tabela 1). Estas condições não satisfazem as exigências de altas temperaturas e luminosidade da cultura, que se desen- volve melhor nas épocas secas, sendo menos suscetível às doenças nos períodos úmidos conforme relatou Witaker \& Davis (1962). Os maiores rendimentos alcançados nos plantios de fevereiro e agosto alicerçam as informações de Yamaguchi, (1983) e Casseres (1984) sobre a melhor adaptação das cucurbitaceas às zonas quentes e semi-áridas, com alta luminosidade e temperaturas de 18 a $30^{\circ} \mathrm{C}$, não tolerando temperaturas baixas. As maiores cotações de preços para Brasília-DF, ocorrem de junho a outubro (Kurihara et al., 1993). Vale ressaltar que o plantio de agosto se enquadra plenamente, para suprir essa demanda de mercado neste período. As menores cotações ocorrem de novembro a janeiro, o que deve-se principalmente à maior ocorrência de plantios, sobretudo de sequeiro (dependentes de chuvas) com e sem consórcio com cereais.
A cultivar de maxixe Quinado sobressaiu-se nas épocas com rendimentos variando de 5,34 a 26,15 t.ha ${ }^{-1}$, com um rendimento médio de 17,50 t.ha $^{-1}$ seguida das cultivares de maxixe Liso, Semi-liso e com Espículos, que não mostraram-se diferenças entre si (Tabela 2). Estes resultados são superiores ao rendimento de 5 t.ha h $^{-1}$ relatado por Filgueira (1981) e concordantes com Yokoyama (1987) que obteve rendimentos variando de 6,6 a 17,1 t.ha $^{-1}$, assim como com Martins (1986) que verificou produções de 16 t.ha- ${ }^{-1}$ nos períodos secos e 8-10 t.ha-1 no período chuvoso.

Com relação ao peso médio de frutos (Tabela 3), observou-se uma variação das cultivares dentro das épocas de plantio de 14,57 a 49,90 g/fruto, com pequena oscilação entre as épocas (23,24 a 29,11 g/fruto), destacando os 
RESENDE, G. M. de. Rendimento de cultivares de maxixe em função de épocas de plantio.

Tabela 4. Número de frutos por planta de cultivares de maxixe em função das épocas de plantio. EPAMIG, Porteirinha-MG ${ }^{1}, 1986$ a 1988.

\begin{tabular}{|c|c|c|c|c|c|}
\hline \multirow{2}{*}{ Cultivares } & \multicolumn{4}{|c|}{ Épocas de plantio } & \multirow{2}{*}{ Médias } \\
\hline & Novembro & Fevereiro & Maio & Agosto & \\
\hline Liso & $21,93 * a$ & $41,27 \mathrm{a}$ & $12,11 \mathrm{a}$ & $36,75 \mathrm{a}$ & $28,02 \mathrm{a}$ \\
\hline Semi-liso & $22,55 \mathrm{a}$ & $34,96 \mathrm{bc}$ & $10,32 \mathrm{a}$ & $35,91 \mathrm{a}$ & $25,94 \mathrm{ab}$ \\
\hline Norte-C & $10,63 \quad b$ & $30,65 \quad c$ & $8,09 \mathrm{a}$ & 28,79 bc & 19,54 \\
\hline Norte-T & $9,78 \quad b$ & $32,53 \quad \mathrm{c}$ & 9,09 a & $33,51 \mathrm{ab}$ & 21,23 \\
\hline Espículos & $18,81 \mathrm{a}$ & $39,43 \mathrm{ab}$ & $8,65 \mathrm{a}$ & $33,67 \mathrm{ab}$ & $25,14 \quad b$ \\
\hline Quinado & 17,38 a & $29,87 \quad \mathrm{c}$ & 7,91 a & $27,56 \quad \mathrm{c}$ & 20,68 \\
\hline Médias & $16,85 \mathrm{C}$ & $34,79 \mathrm{~A}$ & $9,36 \mathrm{D}$ & $32,70 \mathrm{~B}$ & \\
\hline
\end{tabular}

${ }^{1}$ Média de dois anos.

*Médias seguidas pela mesma letra minúscula na coluna e maiúscula na linha, não diferem entre si pelo teste de Tukey ao nível de 5\% de probabilidade.

Tabela 5. Comprimento $(\mathrm{cm})$ de frutos de cultivares de maxixe em função das épocas de plantio. EPAMIG, Porteirinha-MG', 1986 a 1988.

\begin{tabular}{|c|c|c|c|c|c|}
\hline \multirow{2}{*}{ Cultivares } & \multicolumn{4}{|c|}{ Épocas de plantio } & \multirow{2}{*}{ Médias } \\
\hline & Novembro & Fevereiro & Maio & Agosto & \\
\hline Liso & $4,96 * b$ & $5,29 \mathrm{~b}$ & $4,67 \quad b$ & $4,97 \mathrm{~b}$ & $4,97 \mathrm{~b}$ \\
\hline Semi-liso & $4,89 \mathrm{~b}$ & $5,30 \mathrm{~b}$ & $4,37 \quad \mathrm{c}$ & $4,90 \mathrm{~b}$ & $4,87 \mathrm{~b}$ \\
\hline Norte-C & $4,12 \quad \mathrm{~d}$ & $4,67 \quad \mathrm{c}$ & 3,70 & $4,11 \quad \mathrm{~d}$ & $4,15 \quad d$ \\
\hline Norte-T & $4,38 \mathrm{~cd}$ & $5,09 \mathrm{~b}$ & 3,95 & $4,18 \quad d$ & $4,40 \quad d$ \\
\hline Espículos & $4,57 \mathrm{c}$ & $5,13 \mathrm{~b}$ & $4,43 \quad c$ & $4,53 \mathrm{c}$ & $4,66 \mathrm{c}$ \\
\hline Quinado & $5,89 \mathrm{a}$ & $6,51 \mathrm{a}$ & $5,61 \mathrm{a}$ & $5,92 \mathrm{a}$ & $5,98 \mathrm{a}$ \\
\hline Médias & $4,80 \mathrm{~B}$ & $5,33 \mathrm{~A}$ & $4,45 \mathrm{C}$ & 4,77 B & \\
\hline C.V.(\%) & Culti & 3,70 & & & \\
\hline
\end{tabular}

${ }^{1}$ Média de dois anos.

plantios de fevereiro e agosto com melhor desempenho. Pimentel (1985) também detectou uma pequena variação no peso médio entre os períodos seco e chuvoso para as cultivares Lisas e com Espículos, salientando que no período seco, sob irrigação, obtiveram-se os maiores pesos médios de frutos. Quanto às cultivares, "Quinado" sobressaiuse com peso médio de 45,70 g/fruto, seguida de Liso e Espículos (27,35 g e $26,11 \mathrm{~g} /$ fruto, respectivamente), sendo o menor peso (17,78 g/fruto) apresentado pela cultivar Norte-C. Resultados similares foram evidenciados por Yokoyama (1987) para a cultivar Quinado. Ao contrário, Pimentel (1985) observou para cultivares Lisas e com Espículos, pesos médios (30 a 38 g/fruto), superiores aos do presente trabalho, contudo trabalhando com espaçamento de $3,0 \times 2,0 \mathrm{~m}$, pouco competitivo quando comparado ao espaçamento utiliza- do (1,0 x 1,0 m). Yokoyama (1987), trabalhando com 24 populações, verificou que o peso médio de frutos oscilou de 34 a $70 \mathrm{~g}$, com maior frequência de frutos no intervalo de 40 a $50 \mathrm{~g}$. Todavia, estes resultados foram obtidos em cultivos com 5 plantas/parcela no espaçamento de $1,5 \times 1,0 \mathrm{~m}$ e com uma planta/cova.

Quanto ao número de frutos por planta (Tabela 4), nota-se que os maiores índices foram alcançados em plantios de fevereiro e agosto $(34,79$ e 32,70 frutos/planta, respectivamente) e com menor desempenho no período de maio (9,36 frutos/planta), quando ocorrem menores temperaturas, corroborando as afirmações de Casseres (1984), sobre a melhor adaptação das cucurbitáceas às condições de temperaturas e luminosidade mais elevadas. Obteve-se oscilação de 7,91 a 41,27 frutos/planta, destacando-se as cultivares Liso, Semi- liso e Espículos como as mais prolíficas. Estes resultados foram suplantados por Yokoyama (1987) que encontrou variação de 27 a 86 frutos por planta, embora estudando apenas 5 plantas/parcela no espaçamento de $1,5 \times 1,0 \mathrm{~m}$.

No que se refere ao comprimento do fruto (Tabela 5), verificou-se uma oscilação de 3,70 a $6,51 \mathrm{~cm}$, tendo o plantio de fevereiro se destacado nesta característica. $\mathrm{O}$ plantio de maio apresentou o menor tamanho médio de fruto com 4,45 $\mathrm{cm}$, seguido pelo de agosto $(4,77 \mathrm{~cm}) \mathrm{e}$ novembro $(4,80 \mathrm{~cm})$ sem diferença estatística entre si. Entre as cultivares sobressaiu-se a cultivar Quinado que apresentou uma variação de 5,61 a $6,51 \mathrm{~cm}$ no comprimento de fruto. Resultados estes pouco inferiores às observações de Paiva (1994), que encontrou comprimento de fruto de $5,31 \mathrm{~cm}$ em população natural de maxixe e concordantes com Yokoyama (1987) que destacou a 
Tabela 6. Diâmetro transversal do fruto $(\mathrm{cm})$ de frutos de cultivares de maxixe em função das épocas de plantio. EPAMIG, Porteirinha$\mathrm{MG}^{1}, 1986$ a 1988.

\begin{tabular}{|c|c|c|c|c|c|}
\hline \multirow{2}{*}{ Cultivares } & \multicolumn{4}{|c|}{ Épocas de plantio } & \multirow{2}{*}{ Médias } \\
\hline & Novembro & Fevereiro & Maio & Agosto & \\
\hline Liso & $2,81 * b$ & $3,09 \mathrm{~b}$ & $2,90 \mathrm{~b}$ & $2,87 \quad b c$ & $2,92 \mathrm{~b}$ \\
\hline Semi-liso & $2,80 \mathrm{~b}$ & $2,97 \mathrm{bc}$ & $2,78 \mathrm{~b}$ & $2,93 \quad \mathrm{~b}$ & $2,87 \quad b c$ \\
\hline Norte-C & $2,44 \quad \mathrm{c}$ & $2,54 \quad \mathrm{~d}$ & $2,42 \quad \mathrm{c}$ & $2,44 \mathrm{~cd}$ & $2,46 \quad \mathrm{e}$ \\
\hline Norte- $\mathrm{T}$ & $2,67 \mathrm{~b}$ & 2,74 & 2,56 & 2,61 & 2,64 \\
\hline Espículos & $2,75 \mathrm{~b}$ & $2,88 \mathrm{~cd}$ & $2,76 \mathrm{~b}$ & $2,73 \mathrm{de}$ & 2,78 \\
\hline Quinado & $3,59 \mathrm{a}$ & $3,89 \mathrm{a}$ & $3,51 \mathrm{a}$ & $3,62 \mathrm{a}$ & $3,65 \mathrm{a}$ \\
\hline Médias & $2,84 \mathrm{~B}$ & $3,02 \mathrm{~A}$ & $2,82 \mathrm{~B}$ & $2,87 \mathrm{~B}$ & \\
\hline C.V.(\%) & Culti & 5,07 & & & \\
\hline
\end{tabular}

${ }^{1}$ Média de dois anos.

*Médias seguidas pela mesma letra minúscula na coluna e maiúscula na linha, não diferem entre si pelo teste de Tukey ao nível de 5\% de probabilidade.

cultivar Quinado com maior comprimento e diâmetro transversal de fruto. No que se refere ao diâmetro transversal (Tabela 6), o plantio de fevereiro proporcionou o maior diâmetro médio $(3,02 \mathrm{~cm})$, não havendo diferença entre as demais épocas. Ocorreu uma variação de $2,42 \mathrm{~cm}$ a $3,89 \mathrm{~cm}$ dentro das cultivares nas diferentes épocas, tendo a cultivar Quinado apresentado o maior diâmetro médio $(3,65 \mathrm{~cm})$, sendo o menor desempenho obtido pela cultivar Norte-C $(2,46 \mathrm{~cm})$. As variações de comprimento e diâmetro obtidas neste trabalho são equivalentes às obtidas por Tindall (1983) e pouco inferiores aquelas relatadas por Yokoyama (1987) que, trabalhando com espaçamento e menor número de plantas obteve valores mais altos para esta característica.

Deve-se salientar que o bom desempenho das cultivares regionais para as diversas características avaliadas em comparação às cultivares comerciais foi proporcionado pela sua melhor adaptação às condições locais de cultivo. A cultivar Espículos, apesar da pouca aceitação nos mercados consumidores, mostrou-se tão produtiva quanto as cultivares Lisa e Semi-lisa, podendo compor futuros trabalhos de melhoramento, visando a obtenção de cultivares produtivas e adaptadas. $O$ espaçamento utilizado (1,0 $\mathrm{m} \times 1,0 \mathrm{~m}$ com duas plantas/cova) mostrou-se muito competitivo, com ampla cobertura do solo, à exceção do plantio de maio quando é menor o desenvolvimento vegetativo. Uma vez que o plan- tio nesta época resulta em colheita na entressafra, estudos de espaçamento fazem-se necessários para a obtenção de maior rendimento de colheita.

Neste contexto, pelos bons resultados obtidos nas diferentes características analisadas, aliados ao maior interesse das empresas produtoras de sementes e sua boa aceitação nos principais mercados consumidores nacionais, o maxixe desponta como uma hortaliça de grande potencialidade e uma nova alternativa de plantio, sobretudo nos perímetros irrigados, do Norte de Minas Gerais e Nordeste, tanto como para consumo in natura, como para a industrialização.

\section{LITERATURA CITADA}

BAIRD, J.R.; THIERET, J.W. The bur gherkin (Cucumis anguria var. anguria, Cucurbitaceae). Economic Botany, v. 42, n. 3, p. 447 - 451, 1988.

CASSERES, G. Produccion de hortalizas. 3. ed., San Jose: IICA, 1984. 387 p. (IICA. Serie Libros y Materiales Educativos, 42).

CORRÊA, M.P. Dicionário das plantas úteis do Brasil e das exóticas cultivadas. Rio de Janeiro: IBDF/Ministério da Agricultura, 1974. v. 1,1689 p.

FILGUEIRA, F.A.R. Manual de olericultura: cultura e comercialização de hortaliças. 2.ed. São Paulo: Agronômica Ceres, 1981. v. 1, $338 \mathrm{p}$.

GOMES, F. P. Curso de Estatística Experimental. 8. ed., Piracicaba: Nobel, 1987. 430 p.

KOCH, P.S.; COSTA, C.P. da. Herança de caracteres de planta e fruto de maxixe. Horticultura Brasileira, Brasília, v. 9, n. 2, p. $75-76,1991$.
KURIHARA, C.; GOMES, G.C.; MATOS, F.A.C de; QUINDERE JUNIOR, R.A.G. Recomendações técnicas para produção $e$ comercialização de hortaliças para o periodo de entressafra no Distrito Federal. Brasília: EMBRAPA-SPI/EMATER-DF, 1993, $48 \mathrm{p}$.

MARTINS, M.A. de S. Maxixe (Cucumis anguria L.) e seu cultivo em São Luis do Maranhão. São Luis: EMAPA, 1986. 12 p. (EMAPA. Documentos, 8).

PAIVA, W.O. de. Parâmetros genéticos em maxixe sem espículos. Acta Amazonica, Manaus, v. 24, n. 1 - 2, p .3 - 8, 1994.

PATERNIANI, M.E.A.G.Z.; COSTA, C.P. Evaluation of interespecific hybrization in the genus Cucumis L. Revista Brasileira de Genética, Ribeirão Preto, v. 15, n. 2, p. 399 405, 1992.

PIMENTEL, A.A.M.P. Olericultura no trópico úmido: hortaliças da Amazônia. São Paulo: Agronômica Ceres, 1985. 332 p.

QUEIROZ, M.A. de. Potencial de germoplasma de cucurbitáceas no Nordeste Brasileiro. Horticultura Brasileira, Brasília, v. 11, n. 1, p. 7 - 9, 1993.

SATURNINO, H.M.; PAIVA, B.M.; CONTIGO, V.P.M.; FERNANDES, D.P.L.; VIEIRA, G.S. Cucurbitáceas: aspectos estatísticos. Informe Agropecuário, Belo Horizonte, v. 12, n. 2, p. 173 - 175, 1982.

TINDALL, H.B. Vegetables in the tropics. London: Macmillan, 1983. 523 p.

YAMAGUCHI, M. Wold vegetables: principles, production and nutritive values. Westport: Avi, 1983. $415 \mathrm{p}$.

YOKOYAMA, S.; SILVA JÚNIOR, A.A. Maxixe: uma hortaliça pouco conhecida. Agropecuária Catarinense, Florianópolis, v. 1, n. 3, p. 12 - 13, 1988.

YOKOYAMA, S. Genética e produção de sementes de maxixe (Cucumis anguria L.). Piracicaba: ESALQ, 1987. 115 p. (tese doutorado).

WITAKER, T.W.; DAVIS, G.N. Cucurbits: botany, cultivation and utilization. London: Leonard Hill, 1962. 250 p. 